\title{
Gobernar la ciudad. El ayuntamiento de Valencia de la dictadura a la democracia. Un estudio de caso (1969-1979)*
}

\author{
Juan Carlos Colomer Rubio ${ }^{1}$ \\ Universitat de València
}

RESUMEN: Para contribuir al debate sobre el proceso de transición a la democracia, este trabajo de investigación tiene como objetivo el análisis del Ayuntamiento de Valencia en el tardofranquismo y su tránsito desde la muerte del dictador Francisco Franco hasta las primeras elecciones democráticas. Los ayuntamientos franquistas, fuertemente marcados por la figura del alcalde, presidente de la corporación y cabeza visible del poder de la dictadura en el municipio, han sido escasamente analizados por la historiografia, en parte debido por el modelo politico transicional imperante hasta hace pocos años. Este vacio historiográfico obliga a reconstruir, en primer lugar, un estado de la cuestión que nos indique lo analizado pero también los vacios existentes. En segundo lugar, se trazará la panorámica general de los dos líderes municipales más importantes y cuyo mandato político tendrá especial trascendencia: Adolfo Rincón de Arellano y Miguel Ramón Izquierdo. El estudio de los mandatos, el perfil político y la evolución de la institución municipal nos permitirá ver las características que pudo tener el propio proceso de transición a la democracia en la esfera local.

PALABRAS ClAVE: Franquismo; Transición; ayuntamientos; política municipal; Valencia.

* Siglas: Archivo del Reino de Valencia: (ARV). Archivo Municipal de Valencia: (AMV).

1 El autor pertenece al proyecto «De la dictadura nacionalista a la democracia de las autonomías: política, cultura, identidades culturales» [HAR2011-27392] financiado por el Ministerio de Economía y Competitividad. 
To Rule the City. Valencia City Council from Dictatorship to Democracy. A case study(1969-1979)

ABSTRACT: To contribute to the debate on the process of transition to democracy, this research aims at the analysis of the City Counciland Transit tardofranquismo since the death of dictator Francisco Franco until the first democratic elections. Franco Municipalities strongly marked by the figure of the mayor, president of the corporation and visible head of the power of the dictatorship in the municipality, have been little studied by historians, partly because of the transitional political model prevailing until recent years. This requires rebuild historiographical vacuum, first, astate of affairs that we analyzed but also indicated gaps. Second, we draw the overall picture of the two largest municipal leaders whose political mandate will have special significance: Adolfo Rincón de Arellano and Miguel Ramón Izquierdo. The study of mandates, the political profile and the evolution of the municipal institutions allow us to see the features that could have the process of transition to democracy at the local level.

KEY WORDS: Franco; Transition; Municipalities; Local Goverment, Valencia.

\section{INTRODUCCIÓN}

\section{El estudio de los ayuntamientos franquistas como avance en el conoci- miento sobre la Transición}

Todo final de régimen político autoritario e inicio de una etapa democrática incluye un necesario debate historiográfico. ¿Cómo se llegó a la democracia?, ¿de qué forma se transitó?, ¿cuándo se inició el cambio?, ¿qué actores lo favorecieron?, ¿qué elite política pervivió?; multitud de interrogantes que han sido debatidos desde los propios inicios de la crisis del franquismo y transición a la democracia española. Dicha discusión, iniciada por grupos de investigación vinculados a la sociología y politología tuvo su continuidad en determinados sectores de la historiografía y se plasmó en importantes obras que han constituido referentes en el estudio de las transiciones y la democratización.

Pero, en los últimos años, estamos asistiendo a un replanteamiento general del debate. El progresivo distanciamiento de los marcos teóricos planteados por científicos sociales y la apertura de nuevos archivos y centros de investigación, ha llevado a una reformulación de la explicación en torno a la génesis y desarrollo del cambio político en el Estado español en los años setenta. Algunos autores han comenzado a problematizar el propio acontecimiento de la Transición aportando nuevas perspectivas y enfoques, dentro de los cuales pretende insertarse este estudio de caso. A tenor de lo planteado, un trabajo sobre las instituciones locales, concretamente el Ayuntamiento, se convierte 
en necesario si queremos profundizar en el estudio del proceso democratizador a escala local ${ }^{2}$. Por tanto, inserto en un proyecto de tesis doctoral más amplio, planteamos una investigación que analice las políticas, evolución y composición de las instituciones locales del tardofranquismo, acotando el marco espacial en la ciudad de Valencia ${ }^{3}$, siempre en conexión con la propia evolución de todo el Estado español. Así veremos como, para el caso de este Ayuntamiento en el ámbito cronológico de 1969-1979, se va a producir una ruptura de la elite ligada a un falangismo «caudillista» encabezado por Adolfo Rincón de Arellano -alcalde de 1958 a 1969- a una gestión "profesionalizante» del municipio de la mano de Miguel Ramón Izquierdo - al frente del consistorio de 1973 a 1979-. Esta ruptura será la hipótesis que va a marcar el desarrollo de estas páginas: la cesura de la elite al frente, reflejo de una situación general de la dictadura, será factor explicativo del cambio en los setenta. Por tanto, dicha desunión en una serie de proyectos políticos enfrentados, resultó clave para que el cambio se produjese de la forma en que se produjo. Desde la perspectiva local, los diferentes programas de los diferentes alcaldes serán reflejo de esa dialéctica, así como su propia evolución política en el régimen. Junto con ello, rastrear los orígenes ideológicos de los mandatarios locales, sus políticas y la composición de los plenos permite comprender las iniciativas de apertura o no a las demandas de los conciudadanos generando, cuando las hubo, auténticas «escuelas de democracia» que serán claves en el proceso democratizador. Poner la atención sobre ello puede ampliar el conocimiento que tenemos sobre el desarrollo del poder municipal durante la crisis del sistema franquista y la repercusión sociopolítica en los ciudadanos que vivirán la Transición.

Para reforzar la hipótesis de partida veremos, en primer lugar, los lugares comunes del debate sobre el cambio político donde la institución local quedaba relegada a puestos secundarios. Subrayaremos, en segundo término, cómo el peso de los alcaldes en el franquismo será mayor de lo comúnmente señalado, lo que se podrá comprobar en el caso de la ciudad de Valencia en el periodo de la crisis del régimen. El Ayuntamiento de Valencia, a modo de radiografía del período, permite contemplar la ruptura de la elite que se producirá prácticamente en toda España y que nos ayuda a explicar, mejor y con detalle, el proceso de cambio político.

2 Así lo han planteado estudios renovadores en este campo y de los que el presente estudio es deudor: NICOLÁS MARÍN, 2007, 251-267; 1982. MARÍN CORBERA, 2000; 2005. LARRAZA, 2005, 68-79. LÓPEZ AGUDÍN, 72 (1980), 64-73. QUIROSA-CHEYROUZE MÚÑOZ y FERNÁNDEZ AMADOR, 2010. MARTÍN, 2006. MARTÍNEZ, 2003. PONCE ALBERCA, 2008. SÁNCHEZ GONZÁLEZ y PONCE ALBERCA, 36/1 (Missouri, 2011). ENCINAS RODRÍGUEZ, 2008.

3 Para otros marcos espaciales tenemos la combinación de estudios prosopográficos y biográficos entre los que cabe destacar el profuso trabajo sobre los alcaldes de Bilbao. AGIRREAZKUENAGA, 2002-2008. 
Todo ello conducirá a afirmar, al final de nuestro escrito, la importancia de la evolución de los hombres al frente del poder en la dictadura, auténticos constructores del sistema franquista. En esa transformación hacía unos técnicos profesionales -en una clara reconfiguración del poder local- la relación de sumisión al Caudillo se transformará en una identificación con el Estado. Hasta el punto que «esta transformación ideológica fue el sustrato cultural que dará lugar a la dinámica del cambio de régimen» ${ }^{4}$.

\section{A modo de justificación: luces y sombras de un debate historiográfico}

Como venimos afirmando, antes de plantear el estudio de caso debemos resaltar las potencialidades, pero también las carencias, derivadas del propio debate historiográfico. En cualquier campo del conocimiento, el elevado número de bibliografía existente sobre un tema no determina la interrupción de su estudio. Así ha sido en el caso de la Transición española. Con el establecimiento de nuevas democracias participativas, a mediados de los años setenta del siglo XX, una nueva experiencia histórica recorría Europa. Este acontecimiento que suponía el paso de gobiernos autoritarios de larga duración a democracias consolidadas, marcó un antes y un después en la evolución histórica del continente. El cambio, concebido como la construcción de nuevas estructuras políticas se iniciaría en España tras la desaparición física, en 1975, del general Francisco Franco. Su muerte abrió un proceso de transacción política que finalizaría para la mayoría de historiadores en 1981, con el fracaso del golpe de Estado y la consolidación de un sistema democrático en España.

La repercusión social de dicho acontecimiento se tradujo en un gran interés de los científicos sociales que crearon el gran paradigma de los procesos de Transición. Esta novedad interpretativa sintetizada en la inevitabilidad de proceso y la dirección de unos «pilotos del cambio» ${ }^{5}$ tendió a resaltar el considerado instrumento privilegiado de transformación que es el pacto entre los líderes democráticos y los autoritarios, fruto del consenso presente, casi de forma natural, en la propia Transición 6 .

4 GENIEYS, 2004.

5 Es el título de una conocida biografía de Juan Carlos I. El «actor monarquía» ha sido unos de los principales protagonistas para esta interpretación: POWELL, 1991. Otras figuras como la de Adolfo Suárez también ha sido comúnmente ensalzada en obras recientes, véase: HERNÁNDEZ, 2009.

6 A partir de estas características podemos considerar que la experiencia española de Transición a la democracia fue determinante para el establecimiento de un modelo cuya fundamentación, pero también aceptación social, fue dando origen a una versión de la transiciones en general y de la experiencia de Transición española en particular que pasará a formar parte del imaginario colectivo gracias, en parte, a la acción de los medios de comunicación y 
La asunción de los preceptos anteriores generó una serie de líneas de trabajo complementarias 7 . Tenemos los autores que han considerado el tránsito de sistema y sobre todo su final, como el algo esperado y que tenía que darse necesariamente, dada la existencia de una estructura social compleja formada en la última década del franquismo. En palabras de estos teóricos, la modernización social acaecida en los últimos años de la dictadura propició el surgimiento de nuevas clases medias que resultarían el caldo de cultivo de la oferta programática del centrismo político que emitirían Adolfo Suárez y la Unión de Centro Democrático ${ }^{8}$. Junto a estos, tenemos especialistas que conciben el cambio de régimen como resultado de un equilibrio de fuerzas entre reformistas y oposición democrática gracias al factor de negociación política: el famoso consenso. Sería la combinación de esa posibilidad social, voluntad política y asentimiento bajo el miedo incesante de la vuelta de un conflicto armado lo que finalmente conduciría a la negación conjunta del pasado y el compromiso entre las partes en la Constitución de $1978^{9}$.

Pero, pese a que «la Transición es ya historia, no es algo que hoy sea objeto de debate o lucha política, hoy es objeto científico, con el riesgo de que los que no la vivieron la ignoren, la consideren algo obvio, no problemático» ${ }^{10}$, su cuestionamiento va a marcar el debate posterior. En los últimos años, favorecido por el contexto de las políticas de memoria realizadas por el gobierno socialista, varios especialistas han analizado, introduciendo nuevas variables, el final de la dictadura y cómo fue posible la democracia en España. ¿En qué consiste este replanteamiento? ${ }^{11}$ Dichos enfoques han resaltado la iniciativa del cambio «por abajo» dando especial importancia a la lucha sindical y estudiantil, especialmente de CC.OO., como «engranaje de la subversión». Una contienda que va a ir debilitando el franquismo y al gobierno de Arias Navarro hasta su caída en 1976. Esta idea, sostenida entre otros por Pere Ysás y Carme Molinero, aunque también presente en las obras de Álvaro Soto, subraya lo social como potenciador y protagonista -en algunos casos- de la crisis

en última instancia influido por los grandes teóricos de las ciencias sociales, en especial, la ciencia política y la sociología. [HUNTINGTON, 2004; POULANTZAS, 1976; PRZEWORSKI, 1988].

7 Cómo ha afirmado Julio Pérez Serrano, la discusión en torno al proceso de cambio tiene un fuerte condicionamiento político. El peso de las ayudas institucionales se ha hecho presente en la historiografía financiando proyectos, políticas conmemorativas y la inserción destacada de los contenidos en libros de texto. De este modo, las subvenciones han tendido a dar carácter oficial o institucional a ciertos textos e interpretaciones en perjuicio de otros. PÉREZ SERRANO, 2007, 61-76.

8 CASANOVA, 2002.

9 MARAVALL, 1984. TEZANOS, 1989.

10 LINZ, 1996, 21.

11 REDERO, 36 (Madrid, 1999): 261-281. RUIZ, 2002, 183-222. ORTIZ HERAS, 2003. 
y del cambio ${ }^{12}$. Como afirmó Encarna Nicolás, la capacidad represiva de la dictadura en los años sesenta y setenta truncó unas recientes oportunidades vitales y de movilidad social que hacían más vulnerables a quienes actuaban en las filas de la oposición. Sin embargo, nuevas formas de resistencia siguieron desplegándose para la conquista de la democracia ${ }^{13}$.

Estamos ante aportaciones que vienen a incidir en el estudio del final de la dictadura, la polarización de la elite y la movilización social, para entender el proceso posterior ${ }^{14}$. Lo fundamental es que los interrogantes están puestos en la reconstrucción de la fase final del franquismo, quitando valor a la Transición con mayúsculas, para comprobar, entre otras cosas, si la desunión de la clase dirigente del régimen abriendo puertas a la movilización social fue un elemento decisivo y explicativo del cambio posterior a $1975^{15}$ y de qué forma los movimientos sociales, determinadas instituciones y grupos locales, partidos, sindicatos... descartados en el análisis inicial, «conquistaron» con su fuerza y presencia pública el cambio democrático.

Estas interpretaciones no están exentas de cuestionamientos: ¿hasta qué punto la sociedad, en la crisis del franquismo y la Transición, estuvo ciertamente movilizada? ¿las presiones «desde abajo» explican las decisiones que se tomaron en el proceso?

De ese modo, el debate historiográfico en torno a la crisis del franquismo y la Transición española ha sufrido un gran cambio en los últimos años. Nuevos historiadores, muchos de los cuales no vivieron este proceso, están incorporando nuevas preguntas y cuestiones, nuevos documentos y nuevas perspecti-

12 YSÁS, 2004. SOTO, 2005.

13 NICOLÁS MARÍN, 2007, 251- 252.

14 Destacar el reciente debate en torno a este tema entre Ferrán Gallego y Álvaro Soto publicado en el $n^{\circ} 2$ de la Revista Catalana Segle XX en Noviembre de 2009. La discusión se detiene en la importancia del final del régimen y su crisis que conduce sin remedio a la democracia. «Una Transición explicada como una correlación de fuerzas distinta a la que el régimen expresaba, y en la que la oposición determinaba posiciones y ritmos de cambio, aún cuando no lo lograra, por motivos que tienen que ver con la pericia y fortaleza del adversario y con sus propios errores e intereses específicos de partido, convertir la crisis del franquismo en una ruptura democrática». Esta postura de Gallego se contrapone, aunque no de forma plena, a lo planteado por Álvaro Soto cuando afirmaba que el papel de la sociedad civil fue clave para llevar el proceso. Ambos dotan de especial importancia el protagonismo de la sociedad civil. Pero ambos autores conciben de forma diferente el hecho o punto que viene centrando todo este texto: ¿Qué es la Transición? ¿Hubo Transición-con mayúsculas-? Frente a los que piensan que es un proceso indisociable a la crisis del franquismo pero diferente al mismo y necesario con una sociedad civil determinante en un sistema fuerte; están los autores que conciben la democracia como la conquista, más o menos pacífica, lenta y dificultosa, de unos movimientos sociales, en un proceso indisociable a la crisis y agotamiento de un sistema franquista en clara decadencia. Es lo que Paul Preston parafraseó con aquel título: «el triunfo de la democracia».

15 Véase: SAZ, 68 (Madrid, 2007): 137-163 o GALLEGO, 2008. 
vas de análisis que, además de enriquecer la discusión, la han reactivado ${ }^{16}$. En ello ha tenido mucho que ver el desarrollo a escala local de multitud de estudios regionales que han permitido reconstruir este periodo. Trabajos que no son ajenos, en muchos casos, a los problemas y rémoras planteados. Así la discusión se ha centrado en una serie de elementos como: la importancia de la oposición política, sobre todo en el ámbito universitario y sindical, o el auge del nacionalismo periférico en algunas zonas; aspectos como la influencia de la prensa en el período, el desarrollo de determinados partidos o la evolución de instituciones y elites políticas apenas han sido reseñados, pese al avance que han supuesto trabajos recientes ${ }^{17}$.

Ello tuvo una consecuencia fundamental: la inexistencia de un debate sobre la naturaleza y evolución de los diferentes poderes locales en el tardofranquismo y su traslación en la Transición, algo que si que existió con la fase anterior. Y esto olvidó, como veremos en el epígrafe siguiente, el notable peso de los alcaldes en el proceso.

Dar respuesta a esta omisión, por tanto, es nuestra motivación de partida en este estudio de caso sobre la evolución de las instituciones valencianas en el tardofranquismo, su composición y políticas concretas. Así haremos especial hincapié en el Ayuntamiento de Valencia, nada estudiado para el periodo reseñado. El estudio en profundidad de estas instituciones configuradas, como veremos, por la alargada sombra de sus alcaldes en un sistema jerarquizado, las convierte en el campo de estudio fundamental para entender la evolución de la elite franquista valenciana periférica y su traslación hacía el regionalismo u otras culturas políticas, según el caso.

16 Así hemos asistido recientemente al último Congreso Internacional Historia de la Transición en España en Almería en Noviembre de 2011, esta vez para tratar sobre los partidos políticos, junto al desarrollo de los Seminarios de Historia del tiempo presente en Extremadura, las Jornadas de estudios del franquismo y la Transición de la Universidad de Castilla la Mancha, las publicaciones y estudios del Centre d'Estudis sobre les Èpoques Franquista $i$ Democràtica de la Universidad Autónoma de Barcelona, la difusión de la revista Historia del presente o el monográfico dedicado a la crisis y descomposición del franquismo en uno de los últimos números de la revista Ayer.

17 Es el caso de los trabajos inéditos de suficiencia investigadora realizados durante el programa de doctorado del departamento de Historia Contemporánea de la Universitat de València. Entre ellos, cabe destacar el referido a partidos e instituciones como el trabajo inédito sobre el Partit Socialista del País Valencià (PSPV) de Joan Martí o el trabajo de GASCÓ, 2009. 


\section{SER ALCALDE EN EL FRANQUISMO}

En el fondo de la reflexión anterior subyace la idea de dotar de mayor relevancia y complejidad al análisis de las instituciones locales en el franquismo en tanto en cuanto presentes en el tránsito democrático. Estas corporaciones, tras la Guerra Civil, dotaron al nuevo sistema político de una base de dirección que le aportó mayor legitimidad. Y por ello fueron configuradas con un fuerte carácter unipersonal, con un peso notable del mandatario o dirigente al frente.

Así, desde un primer momento, el interés del franquismo fue ocupar los puestos de las antiguas administraciones republicanas. Pronto aparecieron hombres, militares y antiguos conservadores en su mayoría, dispuestos a mandar y sobre los que recayó el peso de la aplicación efectiva de las medidas depuradoras tras la guerra. Para el caso valenciano, tenemos hombres que habían militado en la Unión Patriótica, también antiguos monárquicos, «cedistas», tradicionalistas y algunos falangistas. Los primeros fueron los que ocuparon los cargos al principio ${ }^{18}$. No debemos ignorar que, a medida que avanzó el conflicto y con la victoria de ejército franquista, el partido único tuvo especial protagonismo en el establecimiento de los diferentes mandatarios locales. En todas las provincias fue fundamental la creación e impulso de FET-JONS un nuevo partido, aglutinador de tendencias en diálogo, del cual se extrajeron a los principales líderes junto con excombatientes, jóvenes «jonsistas» y hasta políticos inscritos en partidos de la derecha republicana. Pronto se tuvo claro que, a estas alturas, los hombres de la nueva Falange que hubieran tenido un pasado autonomista o republicano suponían el menor de los problemas, siempre que fuesen gentes «de espíritu, aptas y leales al Caudillo»:

Entre las gentes que el 18 de julio del 36 dieron la batalla al comunismo, las hay de diferentes matices, no todos son falangistas, pero todos son de probada lealtad a la Patria, y todos son útiles para una labor como la municipal. Quiero esto decir que hemos de buscar siempre a los más aptos sin prejuicio de ningún género, aunque esto no signifique que Falange que es siempre la primera en los momentos de sacrificio haya de ser desplazada de los cargos de dirección y responsabilidad. Todo lo contrario, debemos aspirar a que la esencia, el modo de ser de la Falange se infiltre en todos los municipios españoles ${ }^{19}$.

18 Es el caso de los primeros alcaldes del municipio valenciano donde encontramos al tradicionalista, Joaquín Manglano y Cucaló de Montull, barón de Cárcer (1939-1943) o el militar y aristócrata Tomás Trénor Azcárraga, II marqués del Turia (1955-1958). De hecho, la preeminencia de figuras de la aristocracia valenciana al frente del consistorio fue una constante hasta la llegada de Rincón de Arellano en 1958.

19 DUCH, 1995, 117-126. 
Ahora primaba la regeneración de España, hacer, de alguna manera, las cosas como no se habían hecho antes. En estas palabras latía todo un proyecto político monolítico, depurador y centralizador que se concretó en un cambio en los mecanismos para acceder al control de los centros donde se hacía la política. Terminar con el sistema electoral era, para la lógica del franquismo, la mejor forma de garantizar que las elecciones no se falsearan nunca más. Con la supresión de cualquier vestigio democrático desapareció el voto como valor de cambio. Lo que resultó fue la sumisión y la subordinación en sus manifestaciones más puras y el hieratismo más rígido en el ejercicio del poder, algo que no cambió a lo largo de toda la dictadura ${ }^{20}$.

Tal y como anuncia Martí Marín, todos los cargos serían ocupados por nombramiento superior, estableciéndose así una relación de confianza y dependencia de arriba a abajo que solo podía ser resquebrajada en la misma dirección, incluso en el supuesto de una dimisión o en una destitución fulminante ${ }^{21}$.

Esta jerarquización que caracterizaba al régimen franquista, como base para el mantenimiento de la homogeneidad política, es el hilo explicativo de la limitación de las atribuciones municipales, último peldaño de este sistema jerárquico. En este contexto, la figura del alcalde es más un delegado gubernamental que un representante del municipio ante otras instancias de poder. Este hecho presentará una continuidad en todo el franquismo ya que cuando se realicen, a partir de 1948, las elecciones municipales por tercios, el mandatario municipal nunca dejará de ser designado por el gobernador civil ${ }^{22}$.

Frente a ello, ¿cuáles eran las ventajas de obtener un puesto en una gestora local que tenía, como vemos, escaso margen de maniobra y unos presupuestos que las atenazaban? Las circunstancias que acompañaron a la guerra, primero, y a la victoria, después, generaron una serie de bienes e influencias muy preciadas y, en torno a ellas, se hilaron nuevas adhesiones y lealtades. Así, las viejas relaciones de poder se reformularon y las antiguas clientelas se reconstruyeron en torno a los que estaban a punto de ganar la guerra en abril de 1939. Además, estas nuevas redes clientelares giraban en torno a los mandatarios locales quiénes tenían capacidad de maniobra para decidir puestos y cargos, favorecer a determinadas familias, empresas y primar unos intereses frente a otros ${ }^{23}$.

Aquí, como vemos, la figura de los gobernadores civiles, en su mayoría militares, va a ser incluso más importante. Como representantes y delegados permanentes del gobierno eran la primera autoridad, además de jefes provin-

20 CENARRO, 2006, 421-448.

21 MARÍN, 2000, 50-53.

22 DUCH, 1995, 117-126.

23 CAZORLA, 2000, 44. 
ciales del Movimiento, desde la unión de ambos cargos. Es decir, eran el poder del Estado en cada provincia. Lo habitual durante el franquismo fue la rotación de los gobernadores por las distintas zonas para evitar su desgaste y prevenir su fidelización por parte de las redes clientelares del lugar que administraban. Por otro lado, eran los encargados de acudir a Madrid para intentar solucionar los problemas propios, siempre entre los intereses de las redes locales y los del gobierno que, en última instancia, debían representar ${ }^{24}$. Por tanto, la relación del alcalde con los gobernadores civiles era fundamental, ganarse su confianza podía ser síntoma de su continuidad en el cargo o para conseguir, con mayor rapidez y efectividad, sus demandas en favor de la provincia que gobernaban.

El fuerte carácter unipersonal de ambas instituciones -Ayuntamiento y Gobierno Civil- limitó el peso efectivo de los concejales, meros delegados del alcalde en parcelas públicas sin peso político. El pleno del Ayuntamiento no dejó de ser un órgano consultivo, sin presencia de discusión política, pese a que tenemos constancia documental de opiniones divergentes en el seno de dicha institución.

Así, en este sistema de confianzas y relaciones jerárquicas, tener influencia era fundamental para labrarse una buena carrera política. Así lo realizaron los dos alcaldes de la ciudad de Valencia cuyos mandatos analizaremos a continuación. Ambos representan proyectos divergentes dentro del régimen y sus trayectorias justificarían nuestra hipótesis inicial. El primero, Adolfo Rincón de Arellano, representante de esa nueva Falange y cuya vida va más allá de la gestión local de uno de los municipios más importantes de España, intentó administrar determinadas relaciones, interviniendo, de alguna manera, en la construcción de un nuevo mapa político posible tras Franco. El segundo, Ramón Izquierdo, fuerte regionalista, contribuyó a generar un discurso compatible con el marco democrático lo que le permitió, no sin cierta problemática, mantenerse políticamente tras el fallecimiento del dictador.

«UNA IZQUIERDA DEL RÉGIMEN» FALANGISMO Y PODER MUNICIPAL (19581969)

Como veíamos, el proyecto político de la Falange jugó un papel fundamental en la construcción y evolución de las diferentes instituciones locales. Un proyecto que se fue forjando a partir de la amalgama de los intereses conservadores previos a la guerra, combinado con una elite de «camisas viejas» impulsoras de este conjunto político. Este grupo de poder, representado por

24 PONCE, 2008, 126. 
antiguos combatientes y jóvenes impulsores de la FET-JONS, acabó por ser el sector más renovador -en el caso del territorio valenciano- de las políticas sociales y de la gestión local. Pero lo cierto es que la desunión de la clase dirigente del régimen lo fue debilitando progresivamente y propició su caída en 1969. De este proyecto de concepción social de la dictadura se eligió a determinados hombres para que ocupasen cargos locales $\mathrm{y}$, de paso, frenar el peso creciente de otros sectores, como monárquicos o nacionalcatólicos. Un juego de intereses en las diferentes localidades que se puede rastrear perfectamente, como veremos a continuación, si optamos por un análisis micro.

Valencia, a finales de la década de los cincuenta, tuvo que hacer frente a los problemas derivados de la riada del Turia que había asolado la ciudad en octubre de ese mismo año. El consistorio municipal, liderado en aquel momento por un miembro de la elite aristocrática valenciana, realizó ataques públicos a la mala gestión del gobierno central frente a la catástrofe, lo que propició su cese inmediato. La ciudad, por tanto, quedaba desprovista de un líder que pudiera regir la reconstrucción y aplicar las reformas urbanas para que no volviera a repetirse. Urgía la búsqueda, no sin ninguna complicación y retraso, de un hombre del régimen, leal y fiel a los principios del Movimiento que hubiera aprendido la obediencia y sometimiento que requería la dictadura. El hombre elegido era Adolfo Rincón de Arellano ${ }^{25}$.

Me llamaron para ofrecerme el cargo en la madrugada del siete de octubre. Me llamó Posada [Gobierno Civil] Yo me resistí como un león, entre otras cosas porque mi consulta me iba bien y estaba ganando dinero. Pero luego ya me llamó Sanchis, el amigo de Franco, y no pude decir que no ${ }^{26}$.

Con la elección de Rincón se optaba por un excombatiente en la guerra que había ocupado diferentes puestos locales y frenar, de paso, el creciente peso del grupo monárquico en la ciudad. Este alcalde, con una amplia capacidad de adaptarse al medio político, pudo realizar una carrera ascendente dentro del mundo de la política valenciana y española. De hecho, su labor a cargo de la jefatura provincial del Movimiento, integrando a diferentes sectores de la coalición reaccionaria, fue fundamental finalizada la guerra. Su salida de la alcaldía, tras una dimisión ruidosa en 1969, no hizo quebrar su fidelidad política al dictador, sino todo lo contrario, pues será nombrado consejero nacional

25 La figura de Rincón de Arellano (1910-2006) resulta clave para comprender la elite valenciana que tendrá enorme peso en el franquismo. Su extensa carrera política puede ser analizada gracias a la documentación presente en su archivo personal depositado en la Fundación Cañada Blanch de Valencia y de forma microfilmada en el Archivo del Reino de Valencia.

26 PÉREZ PUCHE, 1997, 286. Con el amigo de Franco se refiere posiblemente a José María Sanchiz Sancho, de gran influencia en el entorno político del Pardo y conocido como el mago del Pardo o el Tío Pepe. 
del Movimiento por designación directa de Franco en 1972, puesto en el que permaneció hasta 1976.

$\mathrm{Su}$ personalidad ideológica estuvo fuertemente imbricada, como venimos señalando, por la personalidad de los impulsores de Falange, José Antonio Primo de Rivera y Ramiro Ledesma, de los que era amigo personal ${ }^{27}$. Siempre consciente de la necesidad de una revolución nacional pendiente, su labor política se impregnó por la renovación social, intentando dotar de un estilo propio a su acción de gobierno.

Franco a mí me aguantaba muchas cosas que yo no sé cómo me aguantaba, porque usted calcule que yo en la presidencia de la Diputación hice lo que no ha hecho nadie en España que es la redepuración, o sea, volver a meter prácticamente a todos los que habían tirado por rojos después de la guerra [...] Los volví a meter a todos ${ }^{28}$.

Pese a todo, su posición ideológica fue derivando hacia la Falange de Franco que acosada por los militares, la Iglesia, tradicionalistas y monárquicos, se había mostrado dispuesta a renunciar a elementos esenciales de su propio discurso fascista con la esperanza de desactivar tal acoso. Todo ello a costa de perder ilusión en sus bases y jugando a la carta del caudillaje franquista. Falange permaneció frente a todos reafirmándose como española, católica y tradicional ${ }^{29}$ :

Los curas que había en las prisiones eran curas tradicionalistas y claro, ellos echaban la culpa de la represión a Falange [...] Si los curas que había en las cárceles eran curas que también sacudían a Falange, pues claro, estaban creando un ambiente hostil. O sea, una campaña bien organizada ${ }^{30}$.

Será esa imagen de resistencia, unido a la forja de una personalidad crítica con el régimen, aunque sin llegar a cuestionarlo, la que forjará la personalidad de Rincón de Arellano y su gestión, primero opuesta al gobernador civil Planas Tovar tras la guerra, criticando la fuerte represión de muchos de sus correligionarios, dimitiendo de su cargo como presidente de la Diputación y saliendo después de la alcaldía con un fuerte ruido mediático - el que permitía

27 Antes de la liberación-Varios temas, ARV, Fondo Rincón de Arellano, Microfilm 2896. Rincón fue un personaje fundamental en la construcción de la Falange valenciana. Primero desde su militancia en movimientos estudiantiles conservadores y después en la organización de las JONS, apoyando sin reservas la fusión con Falange, lo que le valió ser nombrado jefe provincial antes de la guerra.

28 Entrevista a Adolfo Rincón de Arellano realizada por el Departamento de Historia Contemporánea de la Universitat de València [DHC-AO/CU133].

29 SAZ, 2003, 369-370. ELLWOOD, 1984.

30 DHC-AO/CU133. 
la dictadura- tras el recambio ministerial de 1969, ahora con el enemigo nacionalcatólico enfrente encarnado en la figura del Opus Dei:

Opino que así como los pertenecientes a una religión deben admitir toda la vida los dogmas, en política no puede ocurrir lo mismo, las circunstancias cambian. No se puede pensar ahora como en 1933 o 1936. Yo soy fiel a las líneas fundamentales: la unidad de España y una acusada conciencia social. [...] Incluso el concepto de Patria, la concepción orteguiana de José Antonio, requiere ser adaptada al tiempo que vivimos ${ }^{31}$.

Rincón de Arellano, representante de aquel falangismo autentico a la espera de la revolución nacional pendiente que salió de la guerra civil ${ }^{32}$, fuertemente influido por la lectura de la «Dotrina del Fascismo» de Mussolini, sus contactos personales con Primo de Rivera y su formación en Roma, donde pudo empaparse del fascismo italiano, resultan claves para moldear todo lo anterior. Aquí aprendió que en un sistema en el que la raza carece de toda importancia, el Estado es el elemento sustancial, el principal artista, el genuino creador. En definitiva, una concepción orgánica del mundo que tiene el Estado como centro: la institución política pone orden, supera los conflictos, las luchas y crea propiamente la nación ${ }^{33}$.

$\mathrm{Su}$ formación y encuadramiento en los sectores falangistas más críticos, opuestos a casi prácticamente todo que proviniera de una escasa «visión acertada de los tiempos», será clave para entender las políticas públicas de su mandato, entre las que cabe destacar el SALTUV. Antecesora de la actual empresa municipal de transportes, son las siglas de la Sociedad Anónima Laboral de Transportes Urbanos de Valencia que tenía por objeto la gestión del transporte público de la ciudad de Valencia y de la población próxima de Mislata. La novedad es que la empresa se constituyó como una sociedad donde los trabajadores eran propietarios de dos acciones de la misma, en un auténtico colectivo autogestionado, donde el control y presencia del Ayuntamiento era casi inexistente.

Junto con ello, tenemos el desarrollo de un urbanismo futurista poco respetuoso con el entorno natural, donde subrayamos dos grandes proyectos: El Plan Sur y la urbanización del paraje natural de El Saler. Ambos planes centraron multitud de titulares y representaban la política de expansión urbanística descontrolada del franquismo. Además, las dos ejecuciones supusieron una lucha interna continua de los miembros elite municipal con los barrios, aso-

31 Número de diciembre de 1969 de la Revista Índice.

32 GÓMEZ RODA, 1995, 127-134.

33 Este libro fue donado por el propio Rincón de Arellano a la Universitat de València. He tomado la idea del blog del profesor Justo Serna. Consultar http://justoserna.wordpress. com/2009/02/07/la-doctrina-del-fascismo/\#comments [Fecha de consulta: 10 de octubre de 2011] 
ciaciones vecinales y movimientos que abrieron la puerta a la reivindicación ciudadana fundamental en la Transición.

Adolfo Rincón de Arellano fue el alcalde del franquismo que más perduró en el cargo hasta su dimisión en 1969. Su sucesor, López Rosat, lo explicaba de la siguiente manera:

Adolfo Rincón de Arellano estuvo al frente del Ayuntamiento alrededor de once años. Hubo un motivo concreto para su dimisión, y es que había tenido un choque personal y político muy fuerte con el que era subsecretario del Interior, un catalán cuyo nombre no recuerdo ahora. Pues bien, resulta que Franco hizo en 1969 un cambio de política, y nombró mucha gente del Opus. Rincón de Arellano había hecho recientemente unas declaraciones bastante críticas con el Opus. El subsecretario le llamó la atención, cosa que Adolfo le sentó muy mal. Entonces se produjo un enfrentamiento considerable ${ }^{34}$.

Su dimisión, debida al ascenso del Opus, el nombramiento de Garicaño Goñi como ministro de la gobernación, en sustitución del veterano Camilo Alonso Vega, y el ascenso de Cruilles de Peratallada como subsecretario del ministerio, llevaron a un conflicto abierto entre las partes. Como aseguraba Rincón:

Creo que una cosa es estar en desacuerdo con el gobierno y otra muy distinta enfrentarse con el Régimen. Yo puedo estar en desacuerdo con un gobierno, pero no estoy en contra del Régimen. Pienso que es imprescindible montar una izquierda del sistema político español ${ }^{35}$.

Pero también podemos llegar a pensar que la evolución de Rincón de Arellano, en palabras de Dionisio Ridruejo, era la de esa Falange real contrapuesta a la «hipotética», una falange que ostentó desde un primer momento el poder tiñendo de «azul» una serie de medidas pragmáticas, generalmente conservadoras y paternalistas y en ocasiones populistas, en palabras de Amando de Miguel $^{36}$. Aunque con Rincón encontramos un componente más: la política como forma de vida que le llevaría a no vacilar presentando una dimisión ruidosa y un proyecto político que consideraba plausible para la realidad social del momento. Y la clave del asunto es que los falangistas no fueron siempre el sector del gobierno influyente, sino más bien el «social», el que atendía a las demandas y los problemas pero nunca el que recogía o ad-

34 Posiblemente con el catalán se refería a Santiago Cruïlles de Peratallada, nuevo subsecretario de Gobernación tras la remodelación ministerial. Hombre de confianza del nuevo ministro de Gobernación: Tomas Garicano Goñi. Entrevista a López Rosat en: ZABALA y MARÍ, 1999, 95-103. Correspondencia con exalcaldes del Ayuntamiento de Valenciacorrespondencia con López Rosat, ARV, Fondo Rincón de Arellano, Microfilm 2920.

35 DHC-AO/CU133.

36 DE MIGUEL, 1978, 195. 
ministraba el dinero, el que marcaba las líneas de la política económica y presupuestaria. En Rincón encontramos una queja recurrente a las políticas sociales que se estaban realizando y, en definitiva, a un franquismo como él no había soñado ${ }^{37}$.

De hecho, esta actitud contestataria verá los cauces de expresión en plena crisis del régimen. Fruto de su experiencia como alcalde y consciente de los problemas que atravesaba el sistema, referidos muchos a la esfera municipal, participó activamente de las reuniones, ponencias y debates derivados del informe político que presentó Luis Carrero Blanco el 1 de Marzo de 1973 ante el Consejo Nacional del Movimiento ${ }^{38}$.

El ya exalcalde se mostró partidario de realizar reformas conducentes a reafirmar la representatividad en vigor y poner los cauces para ampliarla. Consideraba que los diferentes sectores que quedaban representados debían ampliarse y moverse por otro tipo de intereses, incluida cierta oposición:

Aquí la representación municipal tampoco está lograda, su primer tercio adolece de defectos que hemos planteado anteriormente al referirnos a la representación familiar. En el segundo, los representantes sindicales obreros, en su mayoría, dejan de pertenecer a este estamento durante el ejercicio o con posterioridad al desempeño del mismo, dedicándose más o menos plenamente a su función municipal, no apareciendo por sus puestos de trabajo, siendo envidiados primero, y despreciados después por sus propios compañeros ${ }^{39}$.

Por ello sugería que los alcaldes debían ser elegidos por sufragio universal y los candidatos propuestos por un grupo gubernamental y una oposición al régimen. El alcalde debería poder nombrar directamente delegados de servicios para funciones ejecutivas $\mathrm{y}$, por tanto, quedaba con mayores atribuciones que antes. En cambio, el pleno municipal continuaba despojado de funciones ejecutivas para pasar a ser solo un órgano administrativo y consultivo.

37 Rincón de Arellano aparecía en las memorias de Pilar Primo de Rivera como uno de los pocos auténticos falangistas que había intentado construir un sistema similar al soñado por su hermano. PRIMO DE RIVERA, 1983, 185.

38 Presentado por Carrero ante el Consejo Nacional del Movimiento, se trató de una nueva reafirmación de los principios del régimen, una defensa cerrada de sus características y una negativa rotunda a cualquier cambio. Pero, a partir de las anteriores consideraciones, Carrero propuso al Consejo Nacional el estudio de las medidas que aquél considerara convenientes en una serie de puntos como eran: Política cultural, criterios operativos para una política que sirva a la unidad de los hombres y las tierras de España, política económica, social y sindical, formación y promoción de la juventud, desarrollo político desde la base constitucional de las Leyes fundamentales del Reino, relaciones Estado-Iglesia y estudio sobre la juventud. YSÁS y MOLINERO, 2008, 171 y ss.

39 Consejero Nacional designado por Franco-Contestaciones y sugerencias de los consejeros nacionales, ARV, Fondo Rincón de Arellano, Microfilms 2901-2902. 
Aquí pasaría a ser fundamental la creación de una oposición al gobierno aunque fiel a los principios fundamentales. Apoyándose en sus conocimientos médicos sugería:

En el organismo humano hay dos sistemas uno que excita y otro que frena. El simpático y el vago. Yo creo, aunque no por deformación profesional, que dentro del Régimen interesa un sistema que excite y otro que frene. Entre un sistema y otro, yo estoy alineado desde luego con el que excite, esto es, con los españoles que pretenden avances sociales lo más rápidos posible ${ }^{40}$.

En definitiva, la creación de una izquierda del régimen. Aunque la idea parece muy ambigua, como bien se concretó ${ }^{41}$, propuso la autorización de dos grandes asociaciones una más conservadora y otra de acusado sentido social: una asociación de "carácter aperturista, socializador, avanzado y creador». Una «izquierda», en sus palabras, que fomentase la participación en determinadas decisiones y ámbitos relativos a la política, se dirigiera a la reforma de la empresa e impidiese la especulación del suelo y frenase el monopolio de la banca privada por el camino de la nacionalización o por sistemas de competencia sindical. La idea de una «izquierda», defendida por muchos falangistas a la altura de $1969^{42}$, será determinante para entender la evolución del régimen y explican los choques de Rincón con el Opus Dei, esa derecha que había estado ahí siempre, como solía afirmar, conformada como una "santa mafia» y a la que había que combatir con todos los medios ${ }^{43}$.

Todo ello explica que, en un momento determinado, la desunión ideológica presente en la clase dirigente hiciera imposible continuar con un proyecto franquista. Y las posibilidades que se abrían ante la ya cercana muerte del dictador posibilitaban plantear determinados proyectos novedosos que respondían a una cambiante realidad social.

De Rincón conservamos un profuso archivo personal, una dilatada actividad política en cargos de relevancia, y un proyecto político personal, de los múltiples que habría en el inicio de una época de incertidumbre. Todo ello nos lleva a pensar que la salida del franquismo fue una de las posibles de las muchas que habría. A la vez que la multiplicidad de proyectos y formas de hacer política condujeron inexorablemente al final de la dictadura.

40 Número de diciembre de 1969 de la Revista Índice y Consejero Nacional designado por Franco-Contestaciones y sugerencias de los consejeros nacionales, ARV, Fondo Rincón de Arellano, Microfilms 2901-2902.

41 YSÁS y MOLINERO, 2008, 196.

42 Ideas falangistas resumidas en la obra de GARCÍA, 2007.

43 Tomamos aquí la referencia que usa Rincón en su correspondencia cuando se refería al Opus Dei, recomendando a muchos la lectura del libro de YNFANTE, 1970. Temas varios Alcaldía, Dimisión, ARV, Fondo Rincón de Arellano, Microfilms 2930-2931. 
Su mandato, uno de los más largos y monolíticos, contó con importantes apoyos en Madrid, mantuvo relaciones cordiales con los gobernadores civiles y creó una gran red de influencias que le llevaron a ganar, en poco tiempo, el apoyo de gran parte de la elite valenciana. Arellano, como edil municipal, tuvo que hacer frente a los problemas derivados del crecimiento urbanístico y a los nuevos retos que, durante los años sesenta y setenta, la ciudad experimentó dado su creciente peso económico entre las ciudades españolas. Valencia se vio favorecida por los planes de crecimiento económico aplicados, curiosamente, por los enemigos del alcalde, aquellos tecnócratas del régimen que estaban traicionando el espíritu del «Alzamiento nacional»" ${ }^{44}$.

Pese a la ruidosa salida de Rincón, el proyecto falangista había invadido el consistorio en los últimos años y muchos de los concejales se adscribían a dicho proyecto. Ello llevó a buscar a un sustituto continuista, Vicente López Rosat, en una línea aperturista que se adelantó al "espíritu del 12 de febrero» con el establecimiento de plenos públicos, visitas a los barrios para conocer su problemática interna y una actitud más contestataría con sus superiores. A excepción de su antecesor, prontamente se enemistó con el gobernador civil que aprovechó las primeras manifestaciones vecinales multitudinarias para cesarlo en su puesto.

Con su salida, en 1973, se cierra una etapa en la construcción de la dictadura en Valencia pues, a partir de ese momento, se abrirá la puerta a una nueva elite de orígenes e intereses diferentes y cuya forma de entender la política tendrá gran repercusión sociopolítica en el futuro.

\section{«VALENCIANS! MaI CATALANS» Miguel RAMón IzQUiERdo Y EL REgIONA- LISMO BIEN ENTENDIDO (1973-1979)}

El sucesor, tras los años de continuidad de López Rosat, marcó grandes diferencias con los dos alcaldes anteriores. Con Miguel Ramón Izquierdo ${ }^{45}$ estamos ante un claro exponente de la elite económica de la ciudad en los años 60. Este edil, integrado en el imaginario social como «un buen alcalde» ${ }^{46}$ por los supuestos logros que consiguió relacionados con su discurso en defensa de los valores autóctonos, no era un «camisa vieja» ni tampoco había participado de la construcción del proyecto falangista. Se autodefinía como un servidor

44 Gracias a estas ayudas se desarrolló un importante plan de obras públicas. De estos años son la pista de Barcelona y los nuevos accesos de Ademuz y Alicante a la ciudad. Además Valencia vio crecer de forma desordenada su periferia y su población.

45 Para su biografía destacar: PÉREZ PUCHE, 1979; 1998.

46 Así lo recogían los principales diarios locales en el año de su muerte en 2007. (Las Provincias, 18 de Septiembre de 2007). 
del Estado y de la ciudad con un «caudillismo» no tan evidente a diferencia de los dos alcaldes anteriores. De hecho, su tarea municipal era un complemento de su trabajo como abogado pues la simultáneo como decano del Colegio de Abogados y presidente de la Academia Valenciana de Jurisprudencia y Legislación.

Por tanto, estaríamos ante un gestor municipal, prácticamente despegado de cualquier grupo político y cuya gestión se basó en el reconocimiento de la supuesta realidad regional, fomentando un regionalismo que repercutió socialmente. Además, su gestión continuó la senda de determinados grandes proyectos urbanísticos que lograron aumentar su prestigio e influencia social. Aunque, a diferencia de los dos alcaldes anteriores, estos proyectos se basaron en la defensa del entorno natural.

Así, la paralización de la urbanización del entorno natural de El Saler y la devolución del lecho del cauce del rio Turia a la ciudad -ambas situaciones ya centraban las demandas de la ciudadanía años atrás-, contribuyeron a fortalecer su imagen de precursor de la democracia, por el contacto «asiduo» $\mathrm{y}$ «reticente» que mantuvo con las asociaciones de vecinos de gran importancia en los años de Transición que él vivió de lleno. Pero escuchar las reclamaciones realizadas por estos grupos, en clara respuesta a la presión "por abajo», no resultó una constante en su mandato. Pues, aunque avanzará en políticas urbanísticas y sociales solicitadas por las mismas, nunca hasta el punto de configurar con ellas una comisión conjunta de gobierno local, de ningún modo dejó de ser visto como ilegitimo de origen para ocupar el cargo en tiempos de democracia. La prueba más evidente es que nunca se desvinculó ideológicamente de los presupuestos de la democracia orgánica ${ }^{47}$. Y durante su mandato hubo muestras inquebrantables de adhesión y recuerdo constante al «caudillo Franco», como se desprende en los homenajes tras su muerte producidos en el pleno municipal y donde el propio alcalde aseguró:

Hacer constar la profunda aflicción de la corporación Municipal «interprete del sentir del pueblo valenciano» por el fallecimiento de Francisco Franco, caudillo de España, en esta triste hora de nuestra patria [...] en el propósito de permanecer fieles a su ejemplo de patriotismo, hombría de bien y virtudes cristianas [...] Hagamos ahora lo que Franco quisiera: trabajemos todos por España ${ }^{48}$.

Por tanto, el último alcalde franquista de la capital que fue del 18 de septiembre de 1973 hasta el 20 de abril de 1979, tuvo que hacer frente a una serie

47 Las Provincias, 6 de marzo de 1983.

48 Acta municipal que contiene la sesión extraordinaria realizada en el consistorio el veinte de noviembre de 1975 con motivo del fallecimiento de Franco (Acta del pleno de 20 de noviembre de 1975, AMV). 
de problemas derivados de su escasa legitimidad para ostentar el cargo, una vez desaparecido el dictador, y surgidos por el auge de las protestas vecinales, así como de las circunstancias de su nombramiento - pues no pertenecía a ningún proyecto político claramente definido-. En primer lugar, con su nombramiento en sustitución del falangista Vicente López Rosat, se produjo una ruptura tras quince años de alcaldes próximos al Movimiento. Esto, unido a las circunstancias del nombramiento de Ramón Izquierdo, particularmente tenso por la salida precipitada del anterior alcalde tras fuertes discusiones con el gobernador civil, provocó la dimisión de tres concejales muy vinculados a Rosat. Así, debido a su escasa legitimidad, tuvo que hacer frente a las elecciones internas de 1976 -fruto de la nueva ley de corporaciones locales- con la preocupación añadida del que se sabe en la cuerda floja.

Por medio de este proceso electoral votaban los concejales que integraban la corporación municipal y aquí volvía a jugar un papel fundamental el conjunto de lealtades y adhesiones creadas anteriormente. Ramón Izquierdo dimitió para hacer frente a la campaña electoral que le esperaba en los meses siguientes ${ }^{49}$. Además, centró sus esfuerzos en derrotar al contrincante de más peso de los dos que se presentaron, el demócrata-cristiano Serafín Ríos ${ }^{50}$. Presentado por las asociaciones de vecinos y grupos de oposición que buscaban tener, al menos, un período legalmente autorizado de campaña electoral donde poder exponer sus tesis y movilizar a la gente, sirvió para exponer de manera clara las reivindicaciones vecinales no escuchadas por el consistorio años atrás.

El problema derivó de su contienda con Ríos y, por consiguiente, con las asociaciones de vecinos de la capital que acució el problema de la escasa legitimidad y dejó al mandatario tocado para seguir ostentando el cargo. Pese a todo, Ramón Izquierdo venció sin problemas el 25 de enero de 1976. Este problema tendrá su continuidad en 1977, con el triunfo de la izquierda en el País Valenciano, una victoria que forzó otra dimisión de Ramón Izquierdo aunque nunca será aceptada por el gobierno central y «a partir de aquí» la política local se radicalizará en torno al regionalismo anticatalanista.

Lo que de verdad nos interesa de su mandato y supondrá una ruptura con los alcaldes anteriores, repercutiendo y condicionando la propia Transición valenciana, será su pretendida defensa de unos valores genuinamente valen-

49 En el período en el que la corporación municipal quedo vacante, al frente del municipio se situó Antonio Soto Bisquert, cuyo mandato durará un mes escaso y del cual apenas se desprenden datos reseñables a incluir en este estudio de caso.

50 Serafín Ríos Mingarro. Nació en Burriana (Castellón) el 7 de abril de 1937. Ingresó en el cuerpo de Abogados del Estado en 1960. Tras el fracaso en la contienda electoral será reclamado por el gobierno de Adolfo Suárez y en marzo de 1978, designado para ocupar la Secretaría General Técnica de la Presidencia del Gobierno. Ha presidido también el Consejo Rector del Boletín Oficial del Estado y fue responsable de la comisión encargada por el Gobierno de la elaboración de un Plan Informático Nacional. (El País, 28 de abril de 1979). 
cianos -realizada con insistencia-. Esto creó una memoria colectiva de un alcalde anticatalanista y «por consiguiente» verdadero valenciano frente a los intereses catalanes- como se desprende de una supuesta anécdota con el alcalde de Barcelona-:

Durante su mandato como alcalde de Valencia, basándose en el dictamen jurídico hecho desde el Decanato del Colegio de Abogados, impuso la enseñanza del idioma valenciano en las escuelas municipales y publicó los bandos de la alcaldía en valenciano. Como dato curioso y para conocer la dificultad de la utilización de las lenguas periféricas, en una visita de cortesía en fallas el alcalde de Barcelona Enrique Masó al ver los bandos en valenciano le preguntó: 'Y eso ¿cómo lo haces?' a lo que Miguel Ramón le contestó: ‘ßMolt fàcil enviant-los a l’imprenta!'. Masó no pudo aprobar en el Ayuntamiento de Barcelona la regularización de la enseñanza del catalán ${ }^{51}$.

Pero ahora, propiciado por las críticas a su escasa legitimidad, resurgirá con fuerza su defensa del «idioma valenciano» y de los símbolos y tradiciones «patrias» siempre en relación y acatamiento extremo de los principios del Movimiento mientras los hubo, constituyendo así la característica fundamental de su mandato. De hecho, como se extrae de varios de sus discursos públi$\cos ^{52}$, enfatizó siempre la idea de fomentar un «regionalismo bien entendido». Todo esto vio la luz impulsando la fundación, siendo todavía alcalde, de Unió Regional Valenciana, partido de escaso éxito electoral pero importante pues será origen del Unión Valenciana de gran rédito político en los 80 y 90 . En el origen de dicho partido está el rechazo de Ramón Izquierdo a ofertas de otros partidos, presentando su propio partido regionalista con el apoyo de otros sectores como el presidente de la Diputación de Valencia, Ignacio Carrau, cuya figura resulta también digna de un estudio en profundidad ${ }^{53}$. Este partido nació bajo el apoyo de asociaciones falleras y políticas importantes de la ciudad de Valencia como la falla "Els tres doctors», el Circulo Aparisi y Guijarro, las juventudes de Lo Rat Penat y el Grup d'Acció Valencianista (GAV) y

51 VV.AA., 239 (Valencia-2007).

52 Acta de toma de posesión como alcalde en 1973 y acta del discurso de toma de posesión en 1976 (AMV).

53 Carrau presidente de 1973-1979 e íntimo colaborador del último alcalde franquista de la capital, reconoció en 1995 que prestó apoyo económico a grupos de tendencia regionalista como GAV o secundó una gran manifestación desde el balcón del Palacio de la Generalitat porque en un programa de TVE se afirmaba que Ausiàs March había escrito sus poemas en catalán. Con este motivo intentó entrevistarse con Suárez, cosa que no consiguió, aunque sí que recibió el respaldo de líderes importantes del gobierno en el ámbito local o nacional, como Martín Villa. (Declaraciones de Ignacio Carrau al diario Levante, 31 de Diciembre de 1995). Todos estos datos nos llevan a pensar que un estudio de la última Diputación franquista sería interesante para una investigación similar a la que estamos realizando en estas páginas. 
en torno a un discurso en defensa de la supuesta «mancillación de las señas de identidad valencianas por parte de partidos catalanistas de la región» De este modo, URV, defensora del secesionismo lingüístico, de la bandera tricolor, y del topónimo «Reino de Valencia», dará lugar al valencianismo conservador basado en esencias regionales muy incentivadas en la época anterior desde la municipalidad. Consecuente con su origen acusará al centro y a la izquierda de «sustituir la identidad valenciana por la catalana» al querer imponer unos símbolos y una lengua distinta y extraña a la identidad de los valencianos. Y esto era en 1978 y financiado desde el poder local ${ }^{54}$. La defensa del regionalismo calará hondo en la ciudad generando un autentico movimiento anticatalanista, conocido como «blaverismo» que condicionará el proceso estatutario y autonomista ${ }^{55}$.

En 1979, con las nuevas elecciones municipales y enteramente democráticas, «D. Miguel» se marchará y con él los 22 concejales del consistorio, pues ninguno fue llamado por las candidaturas que entraban en contienda electoral. El resultado cambió el panorama político, el pueblo optó por el partido socialista y la izquierda para iniciar la «aventura democrática municipal». Pero las reminiscencias del franquismo no habían desaparecido: quedaba parte de su personal político -que continuó en partidos de cierto rédito electoral- y un regionalismo que condicionará políticamente el proceso democratizador. Otros problemas como la realización de los dos grandes proyectos pendientes: la conservación del paraje natural de El Saler o el uso que se debía dar al antiguo cauce del río Turia, debieron esperar al primer gobierno democrático municipal.

\section{A MODO DE CONCLUSIÓN}

Junto a la mengua en el consenso sobre el modelo español de democratización, se ha producido también una mayor voluntad de cuestionar los límites de ese modelo. Cuando los teóricos de la democratización a finales de los noventa pasaron de estudiar la Transición a estudiar la consolidación demo-

54 Este grupo político sobrevivió hasta 1982, año en el que se integró en la nueva Unión Valenciana, de la cual Ramón Izquierdo fue fundador, secretario general y posteriormente presidente. En este grupo se presentó en las elecciones generales de 1982 siendo elegido diputado al Congreso por Valencia en las listas junto a Alianza Popular. En los comicios generales de 1986 volvió a ser elegido Diputado para la $3^{\text {a }}$ legislatura (1986-1989), en las listas que Unió Valenciana presentó en solitario, convirtiéndose así en el primer diputado nacional de esta formación.

55 Sobre la influencia del blaverismo en la Transición valenciana véase: COLOMER RUBIO, 2012. CUCÓ, 2002. 
crática, empezaron a discutir la calidad del régimen democrático que emergió de dicha vía de Transición ${ }^{56}$.

Como afirmaba la historiadora Pamela Radcliff, el cuestionamiento de este modelo que, como hemos ido analizando en estas páginas, tuvo su origen en los estudios de sociólogos y politólogos, ha ido perdiendo peso frente a nuevos estudios centrados en analizar el sistema democrático resultante para ver sus límites, carencias, y posibles vías de mejora. Una vez más, las necesidades propias de nuestro presente llevan a mirar al pasado, a aquella «inmaculada Transición», para determinar qué problemas pudieron derivarse de aquellos logros.

Posiblemente habría que empezar a pensar el proceso desde otras perspectivas y enfoques, entre ellos el notable peso que pudo tener la sociedad civil, organizada en múltiples asociaciones, grupos políticos o casas regionales. Pero también ver el propio freno impuesto desde arriba a unas manifestaciones pensadas como desestabilizadoras y determinantes para entender todo el proceso. El personal político que lideró las instituciones municipales, primer ámbito de referencia política de la ciudadanía, unido a las políticas que condujeron a determinados grupos políticos a una mayor expresión democrática $o$ no, es lo que hemos ido analizando en estas páginas. De la forma en la que se hizo la Transición, sobre todo en los pueblos y ciudades, nos permitirá reconstruir todas las variables y caras de este proceso. Pues, con la premisa de tener controlado el Estado para luego democratizar el municipio, se fueron retrasando los procesos electorales de las municipalidades creando la problemática del mantenimiento del personal político anterior en unas instituciones políticas fundamentales. Un personal político que pasará, prácticamente sin solución de continuidad, a nuevas fuerzas democráticas, ya sea en el centrismo de la propia UCD o en los nuevos grupos regionalistas, gracias al allanamiento del terreno que habían realizado en años anteriores.

Pero lo fundamental, y como avanzábamos al inicio, es que la desunión de la elite dirigente, aglutinada en diferentes proyectos políticos enfrentados, fue clave para el progresivo distanciamiento social y desintegración de la dictadura. Esa división provocó un claro enfrentamiento sobre de qué manera atender las diferentes demandas sociales planteadas. Dichas dudas fueron solventadas por la dictadura primero con violencia y después con el progresivo recambio de la elite al frente-gobernadores civiles y alcaldes, sobre todo- que cerraron la puerta a cualquier horizonte democrático hasta 1979. Así, los últimos consistorios franquistas no abrieron sus puertas a cierta liberalización. Esto fue debido a que su interés no radicaba en un avance hacia la democracia que pudiese desestabilizar el sistema, desvirtuándolo. Eran gestores, debían evitar

\footnotetext{
56 RADCLIFF, 2010, 276-277.
} 
la quiebra de las arcas municipales, favorecer los intereses de determinadas familias, empresas y principalmente no atentar contra los principios del Movimiento mientras los hubo. En el caso del último alcalde Ramón Izquierdo, simpatizante de los principios del régimen y fervientemente continuista, pensaba en dar algo de voz a los vecinos pero la justa, evitando cualquier participación que fuera más allá de pequeñas peticiones al consistorio sobre temas que no implicasen democracia, elecciones libres, etc.

Como vemos en un artículo de Valencia Semanal ${ }^{57}$ que analizaba la política municipal de este consistorio, esta capacidad de desoír cualquier propuesta proveniente de asociaciones de vecinos o partidos políticos tendrá consecuencias negativas para el futuro. Además, en segundo lugar, el consistorio asumirá una política no democrática en sus decisiones produciendo también un gran poder de la elite económica dentro del Ayuntamiento. Este poder municipal, como forma de perpetuación política tras Franco, va a intentar trasmitir y potenciar su propio modelo de Estado autonómico, siguiendo las directrices del «regionalismo bien entendido» y como vía para mejorar la centralización, aunque sin acabar con la misma. Muy alejado del «caudillismo» de Rincón de Arellano, el último alcalde franquista llevó a cabo una lucha prácticamente personal, en contra de los símbolos o términos contrarios a su idea autonómica -la bandera sin franja azul semejante a la catalana, término País Valenciano o unidad de las lenguas de origen catalán- Lo que nos lleva a plantearnos nuevas cuestiones claves para entender la influencia sociopolítica en la población: ¿Qué políticas, partidos, o asociaciones culturales relacionadas con ese regionalismo financió el gobierno local durante el mandato de Ramón Izquierdo? ¿Qué papel tuvieron en todo ello los diferentes regidores del consistorio? ¿Qué importancia en el fomento de ese regionalismo tuvieron otras instituciones locales tardofranquistas? ${ }^{58}$

Resulta, por tanto, fundamental analizar e intentar responder, como hemos hecho, el propio papel de las instituciones municipales en el tardofranquismo y ver cómo el poder omnímodo de los alcaldes, unido al desarrollo de políticas y prácticas concretas, indisociables a la formación ideológica de los mandatarios locales y muchas de ellas pensadas en "ganar la paz», marcarán el propio devenir del proceso transicional ${ }^{59}$. Además, las tensiones de los proyectos políticos presentes en los consistorios irá desgastando la dictadura hasta que suceda el hecho biológico o desaparición del dictador. Unos proyectos que se pueden observar en las políticas concretas y en la actitud de los alcaldes. La confrontación de los diferentes programas, que tienen en lo local su máxima representación, explica el progresivo desgaste de la dictadura. Algo

57 PÉREZ PUCHE, 1 (Valencia, 1977).

58 Parte de estas cuestiones han intentado responderse en: COLOMER RUBIO, 2012.

59 Es lo que ha realizado recientemente desde una perspectiva más amplia: CHEYROUZE MÚÑ̃Z, R. y FERNÁNDEZ AMADOR, 2010. 
que será aprovechado por las críticas al régimen y posibilitó, al final, su transformación. En definitiva, con el Caudillo desaparecido sólo quedaba el recuerdo y se abría un nuevo horizonte para los alcaldes franquistas: un paso de la vida a la muerte o, en algunos casos minoritarios, de la muerte a la vida.

\section{BIBLIOGRAFÍA}

Agirreazkuenaga, Joseba (dir.), Diccionario biográfico de los alcaldes de Bilbao, Bilbao, Ayuntamiento de Bilbao, 2002-2008.

Casanova, José, "Modernización y democratización: reflexiones sobre la Transición española a la democracia", en Teresa Carnero (coord.), Modernización, desarrollo político y cambio social, Madrid, Alianza, 2002; 235-276.

Cazorla, Antonio, Las políticas de la victoria: la consolidación del nuevo Estado franquista (1938-1953), Madrid, Marcial Pons, 2000.

Cenarro, Ángela: "Instituciones y poder local en el 'Nuevo Estado", en Santos Juliá (coord.), República y guerra en España (1931-1939), Madrid, Espasa, 2006; 421-448.

Colomer Rubio, Juan Carlos, “'El regionalismo bien entendido': Una política de construcción nacional", en Ferrán Archilés e Ismael Saz (coord.), La nación de los españoles, Valencia, Publicaciones de la Universitat de València, 2012; 379-392.

Cucó, Alfons, Roig i Blau. La transició democràtica valenciana, Valencia, Tàndem, 2002.

De Miguel, Armando, Sociología del franquismo, Barcelona, Éxito, 1978.

Duch, Montserrat, "Falangismo y personal político en los ayuntamientos españoles (1948-1954)", en VV.AA., Comunicaciones presentadas al II Investigadores del Franquismo, Valencia, Institut de Cultura Juan Gil Albert, 1995; 117- 126.

Ellwood, Sheelagh, Prietas las filas: historia de la Falange Española, 1933-1983, Barcelona, Crítica, 1984.

Encinas Rodríguez, David, El Ayuntamiento de Valladolid en la Transición (19731987). Política y gestión, Tesis doctoral, Universidad de Valladolid, 2008.

Gallego, Ferrán, El mito de la Transición, Barcelona, Crítica, 2008.

García, Juan, La Falange imposible, Barcelona, Ediciones Nueva República, 2007.

Gascó, Patricia, UCD-Valencia. Estrategias y grupos de poder político, Valencia, Publicaciones de la Universitat de València, 2009.

Genieys, William, Las élites españolas ante el cambio de régimen político. Madrid, CIS, 2004.

Gómez Roda, Alberto, "La primera jefatura provincial de FET-JONS de Valencia, 1939-1943”, en VV.AA., Comunicaciones presentadas al II Investigadores del Franquismo, Valencia, Institut de Cultura Juan Gil Albert, 1995; 127- 134.

Hernández, Abel, Suárez y el rey, Madrid, Espasa, 2009. 
Huntington, Samuel Phillips, La tercera ola: la democratización a finales del siglo $X X$, Barcelona, Paidós, 2004

Larraza, María del Mar, "El ayuntamiento pamplonés en el tardofranquismo", en VV.AA., Actas del Congreso 'La transición de la dictadura franquista a la democracia', Barcelona, Cefid-UAB, 68-79.

Linz, Juan José, "La Transición española en perspectiva comparada", en Javier Tusell y Álvaro Soto, Historia de la Transición, 1975-1986, Madrid, Alianza, 1996;

López Agudín, Fernando, "Los ayuntamientos de la Transición", Tiempo de Historia, 72 (Madrid, 1980): 64-73

Maravall, José María, La política de la Transición, Madrid, Taurus-Alianza, 1984.

Marín Corbera, Martí, Josep María de Porcioles: catalanisme, clientelisme i franquisme, Barcelona, Base, 2005.

Marín Corbera, Martí, Els ajuntaments franquistes a Catalunya: politica i administració municipal, 1938-1979, Lleida, Pagès, 2000

Martín, Oscar, Albacete en Transición: el Ayuntamiento y el cambio político, 19701979, Albacete, Instituto de Estudios Albacetenses, 2006.

Martínez, María del Carmen, "Fin del régimen franquista e inicio de la Transición en la Diputación de Córdoba: 1972-1979”, en VV. AA, La transición a la democracia en España: actas de las VI Jornadas de Castilla-La Mancha sobre Investigación en Archivos, Guadalajara, Anabad, 2003;

Nicolás Marín, Encarna, Instituciones murcianas en el franquismo (1939-1962). Contribución al conocimiento de la ideología dominante, Murcia, Editora Regional de Murcia, 1982.

Nicolás Marín, Encarna, "“La Transición se hizo en los pueblos'. La vida política en Murcia (1968-1977)”, en Rafael Quirosa-Cheyrouze Múñoz (coord.), Historia de la Transición en España, los inicios del proceso democratizador, Madrid, Biblioteca Nueva, 2007; 251-267.

Ortiz Heras, Manuel, "Historiografía de la Transición", en VI jornadas de Castilla la Mancha sobre investigación en archivos, Guadalajara, Anabad, 2003.

Pérez Puche, Francisco, La Valencia de los años setenta: tal como éramos, Valencia, Ayuntamiento de Valencia, 1998.

Pérez Puche, Francisco, Hasta aquí llegó la riada, Valencia, Ayuntamiento de Valencia, 1997.

Pérez Puche, Francisco, 50 alcaldes: el Ayuntamiento de Valencia en el siglo XX, Valencia, Prometeo, 1979.

Pérez Puche, Francisco, "Ni democracia ni presupuesto", Valencia Semanal, 1 (Valencia-1977).

Pérez Serrano, Julio, "La Transición a la democracia como modelo analítico para la historia del presente: un balance crítico", en Rafael Quirosa-Cheyrouze (coord.), Historia de la Transición en España. Los inicios del proceso democratizador, Madrid, Biblioteca Nueva, 2007; 61-76. 
Ponce Alberca, Julio (coord.), Guerra, franquismo y Transición. Los gobernadores civiles en Andalucía (1936-1979), Sevilla, Centro de Estudios Andaluces, 2008.

Poulantzas, Nicos, Las crisis de las dictaduras, Portugal, Grecia, España, Madrid, Siglo XXI, 1976.

Powell, Charles, El piloto del cambio: el rey, la monarquía y la Transición a la democracia, Barcelona, Planeta, 1991.

Primo de Rivera, Pilar, Recuerdos de una vida, Madrid, Dyrsa, 1983.

Przeworski, Adam, "Algunos problemas en el estudio de la Transición hacia la democracia”, en Guillermo O'Donell, Philippe Schmitter y Laurence Whitehead (eds.), Transiciones desde un gobierno autoritario. Perspectivas comparadas, Barcelona, Paidós, 1988.

Quirosa-Cheyrouze Múñoz, Rafael y Fernández Amador, Mónica, Poder local y Transición a la democracia en España, Granada, CEMCI, 2010.

Radcliff, Pamela, "La Transición española ¿un modelo global?", en Nigel Townson (ed.), ¿Es España diferente?, Madrid, Taurus; 2010, 276-277.

Redero, Manuel, "Apuntes para una interpretación de la Transición política en España”, Ayer, 36 (Madrid 1999): 261-281.

Ruiz, David, La España democrática (1975 - 2000) Política y sociedad, Madrid, Síntesis, 2002, 183-222

Sánchez González, Carlos y Ponce Alberca, Julio, "Difficult Years in the Ayuntamientos, 1969-1979. The Transition to Democracy in Spanish Municipalities", Bulletin for Spanish and Portuguese Historical Studies, 36/1 (Missouri, 2011):

Saz, Ismael, España contra España. Los nacionalismos franquistas, Madrid, Marcial Pons, 2003.

Saz, Ismael, "Mucho más que crisis políticas: el agotamiento de dos proyectos enfrentados", Ayer, 68 (Madrid, 2007): 137-163.

Soto, Álvaro, Transición y cambio en España: 1975-1996, Madrid, Alianza, 2005.

Tezanos, José Félix (et. al.), La Transición democrática española, Madrid, Sistema, 1989.

VV.AA., «Homenaje a Miquel Ramón i Izquierdo», SOM: Revista de la Entitat Cultural Grup d'Acció Valencianista, 239 (Valencia, 2007).

Ynfante, Jesús, La prodigiosa aventura del Opus Dei: génesis y desarrollo de la santa mafia, Ruedo Ibérico, 1970.

Ysás, Pere, Disidencia y subversión. La lucha del régimen franquista por su supervivencia, 1960-1975, Barcelona, Crítica, 2004.

Ysás, Pere y Molinero, Carme, Anatomía del franquismo. De la supervivencia a la agonía, 1945-1977, Barcelona, Crítica, 2008.

Recibido: 05-05-2011

Aceptado: 08-10-2012 